\title{
Monitoring of changes in illicit drugs, alcohol, and nicotine consumption during Ramadan by wastewater analysis
}

Evsen Yavuz Guzel ( $\nabla$ evsen_yavuz_112@hotmail.com )

Cukurova Universitesi https://orcid.org/0000-0002-8029-9254

\section{Research Article}

Keywords: wastewater-based epidemiology, ecstasy, marijuana, Ramadan, illicit drugs, nicotine, alcohol

Posted Date: January 17th, 2022

DOI: https://doi.org/10.21203/rs.3.rs-1213131/v1

License: (c) (i) This work is licensed under a Creative Commons Attribution 4.0 International License. Read Full License 


\section{Abstract}

Illicit drug use is a global problem and represents social, economic, and health burden on society. Wastewater-based epidemiology is an approach based on calculating the consumption of substances in the target population by analyzing the concentrations of human metabolic excretion products of licit and illicit substances in wastewater. The relationship between Ramadan and the consumption of illicit drugs, alcohol, and nicotine (cocaine, benzoylecgonine, amphetamine-like stimulants (amphetamine, methamphetamine, extacy (3,4-Methylenedioxymethamphetamine)), opiates (morphine and heroine); marijuana ( $\mathrm{THC}-\mathrm{COOH})$; ethyl sulfate and cotinine) was discussed based on the wastewater analysis results. This study aims to estimate the changes in the consumption of illicit drugs, alcohol, and nicotine in Adana Province during Ramadan as compared to normal periods using wastewater-based epidemiology. An overall decrease was observed fort he Ramadan Period, most strongly for ecstasy (29\%) followed by heroin (19\%). For cocaine, the variation was slightest (8.6\%). For ecstasy, heroin, nicotine, and alcohol the differences were statistically significant but not for cocaine, amphetamine, methamphetamine, and marijuana. The study presented firstly data about the number of illicit drug, alcohol and nicotine users during and after Ramadan.

\section{Highlights}

- Wastewater-based epidemiology can provide information on drug, alcohol and nicotine consumption during Ramadan.

- Illicit drugs, nicotine and alcohol use were assessed during Ramadan and normal week.

- Illicit drug consumption decreased 8.6-29\% during Ramadan.

- A decrease of $26 \%$ in alcohol consumption and $25 \%$ in nicotine consumption detected during Ramadan.

\section{Introduction}

Illicit drug use is a global problem and a social, economic, and health burden on society (Castiglioni et al. 2006). Consumption of illicit drugs, alcohol, and nicotine in cities or regions during musical events and festivals are often monitored through questionnaires, patient medical records, and police reports (Mackul'ak et al. 2019). However, data obtained by these methods may be affected by subjective factors. While monitoring of selected compounds in wastewater improves data accuracy (Thomas et al. 2012; Ort et al. 2014; van Wel et al. 2016b, a). Wastewater-based epidemiology (WBE) is an increasingly popular approach to provide information on drug use and abuse due to its objectivity, cost-effectiveness, and ability to reveal near real-time data (Lorenzo and Picó 2019; Verovšek et al. 2020). WBE is based on the identification of human metabolic excretion products (biomarkers) of licit and illicit drugs in wastewater (Zuccato et al. 2005; Zarei et al. 2020). It also allows tracking of temporal variations in drug consumption to identify trends and compare drug use across cities, regions, and countries (Daglioglu et al. 2019; Verovšek et al. 2020). 
Since its first implementation by Zuccato, Castiglioni and Fanelli (2005), WBE has been continuously developed and improved (Castiglioni et al. 2013). For instance, in 2012 a group of scientists supported by the European Monitoring Center for Drugs and Drug Addiction (EMCDDA) and the European Cooperation in Science Technology (COST) programme founded the Sewage analysis CORe group (SCORE) to bring experts together to discuss, develop and standardize the WBE approach. (EMCDDA 2016). In 2020, studies covering 82 cities and 18 countries in the European Union including Adana in Turkey were carried out (EMCDDA 2021). The standard of sample preparation and liquid chromatography-mass spectrometry (LCMS/MS) used in this study were confirmed by quality control, and inter-laboratory exercises carried out by the SCORE group.

There are many studies on the assessment of illicit drugs, alcohol, and nicotine consumption in countries such as China (Gao et al. 2017), Canada (Metcalfe et al. 2010), Greece (Gatidou et al. 2016), Finland (Kankaanpää et al. 2016) via WBE. In Turkey, such studies have gained momentum in the last 5 years (Daglioglu et al. 2019, 2021; Mercan et al. 2019; Guzel et al. 2020; Asicioglu et al. 2021; Kuloglu et al. 2021). WBE has been used to investigate changes in using illicit drugs, alcohol, and nicotine on various occasions (festivals, special events, COVID-19 pandemic period, etc.) (Mackul'ak et al. 2015; van Wel et al. 2016a; Mackulak et al. 2019; Benaglia et al. 2020; Bijlsma et al. 2020). In this study, Ramadan, an important month for Muslim communities, was chosen as example.

Ramadan, the ninth month of each year on the Islamic calendar, adult Muslims must refrain from consuming any food, drinks, or oral medication from sunrise to sunset (Aveyard et al. 2011; Hershkop and Bisharat 2020). During Ramadan, Muslim communities fast for one month as a part of their beliefs. Moreover, the month of Ramadan is a period during which Muslims are expected to manifest that they have control over their physical desires (Çelen 2015). Since Ramadan can occur in any of the four seasons, the fasting time varies between 11 hours and 18 hours per day, depending on sunrise and sunset (Aslam and Assad 1986). During this fasting period, life rhythms and habits differ from one country to another (Aadil et al. 2004). The majority of population of Turkey is Muslim (European Comission (EC) 2019). In 2019, when this study was conducted, Ramadan lasted from Monday, May 6, to Monday, June 3.

In this study, the illicit drugs analysed cocaine (COC) by its main metabolite benzoylecgonine (BE), amphetamine $(\mathrm{AMPH})$, methamphetamine $(\mathrm{METH})$, ecstasy (3,4-methylenedioxymethamphetamine (MDMA), morphine and heroin (HER), marijuana by its metabolite 11-nor-9-carboxy- $\Delta^{9}$ tetrahydrocannabinol (THC-COOH), alcohol (ethanol) by its metabolite ethyl sulfate (EtS), and nicotine by its metabolite cotinine. The present study aiming at estimating the consumption of these 6 illicit drugs, alcohol, and nicotine is the first to show changes in their consumption during Ramadan by WBE.

\section{Materials And Methods}

\subsection{Standards and materials}

$\mathrm{COC}, \mathrm{BE}, \mathrm{AMPH}, \mathrm{METH}, \mathrm{MDMA}, \mathrm{HER}, \mathrm{THC}-\mathrm{COOH}$, and their deuterated analogues used as internal

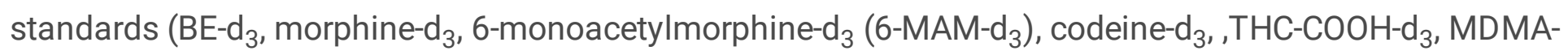


$d_{5}$, COC- $d_{3}$ ) were purchased from Lipomed (Arlesheim, Switzerland). EtS and EtS- $d_{5}$ were obtained from Restek (Bellefonte, PA, USA). Nicotine, nicotine- $d_{3}$ cotinine, and cotinine- $d_{3}$, were purchased from Toronto Research Chemicals (TRC) (Ontario, Canada). Oasis HLB cartridges $(6 \mathrm{~mL} / 500 \mathrm{mg}$ ) were obtained from Waters Corporation (Milford, MA, USA). Glass-fiber filters (Whatman ${ }^{\circledR}$ glass microfiber filters, Grade GF/F, $0.7 \mu \mathrm{m}$ ) were purchased form Merck, (Darmstadt, Germany) as well as ammonium acetate, liquid chromatography grade methanol, ultrapure water, acetonitrile, and acetic acid ( $98 \%$ purity).

\subsection{Sampling period and location}

Adana Province is the sixth largest province of Turkey with a population of 2.2 million. Samples were collected from Seyhan waste water treatment plant (WWTP), the biggest in Adana serving 1.151.000 people, for one week during Ramadan (21-27 May 2019) and one week after Ramadan as a normal week (11-17 June 2019). During the sampling period, the average WWTP influent flow rate was $164600 \mathrm{~m}^{3} /$ day.

\subsection{Wastewater sampling}

Composite 24-hour influent samples were collected for 7 days starting on Tuesday of each week at $09.00 \mathrm{~h}$ and transferred to the laboratory in an icebox $\left(<4^{\circ} \mathrm{C}\right)$. Wastewater samples of $100 \mathrm{~mL}$ were taken every half hour using an automatic sampler (ASP-Station 2000, vacuum system RPS20 Endress+Hauser, Reinach, Switzerland) into $250 \mathrm{~mL}$ PET bottles. The samples were stored in a freezer at $-20^{\circ} \mathrm{C}$ and analysis was completed within 48 hours.

\subsection{Analytical procedure and data treatment}

\section{Sample preparation and extraction}

The samples were filtered with $0.7 \mu \mathrm{m}$ glass-fiber filters an internal standard mix containing cotinine- $\mathrm{d}_{3}(2$ $\mathrm{ng} / \mathrm{L})$, nicotine- $\mathrm{d}_{3}(20 \mathrm{ng} / \mathrm{L})$, and individual deuterated internal standards $(20 \mathrm{ng} / \mathrm{L})$ of each drug were added to water samples were passed through Oasis HLB cartridges. The extraction methods for the illicit drug analysis, and alcohol (EtS) and nicotine (cotinine) analysis were used according to Daglioglu et al. (2020) and Guzel et al. (2020).

\section{Instrumental analysis}

Chromatographic analyses were carried out by LC-MS/MS (CBM-20A LC equipped with SIL-20A/HT automatic sampler and 8030 mass spectrometer, Shimadzu, Kyoto, Japan). Aliquots of $10 \mu \mathrm{L}$ were injected and separated by gradient chromatography at a flow rate to $0.4 \mathrm{~mL} / \mathrm{min}$ at $40^{\circ} \mathrm{C}$ using a pentafluorophenylpropyl (PFPP) column ( $50 \mathrm{~mm} \times 2.1 \mathrm{~mm}, 5 \mu \mathrm{m})$ (Restek Allure®, Bellefonte, PA, USA). The gradient program was: component $A(10 \mathrm{mmol} / \mathrm{L}$ ammonium formate in ultrapure water) plus $5 \% \mathrm{~B}$ (methanol) maintained for $0.1 \mathrm{~min}$, linearly increased to $95 \% \mathrm{~B}$ in $10 \mathrm{~min}$, isocratic for $5.0 \mathrm{~min}$, followed by return to the initial conditions in $0.05 \mathrm{~min}$, and equilibrationfor $4.95 \mathrm{~min}$; total run time was $20 \mathrm{~min}$. For quantitative mass spectrometric analysis, electrospray ionization in the positive (ESI+) and multiple reaction monitoring were used. 
EtS was separated chromatographically using a biphenyl column (100 mm $\times 2.1 \mathrm{~mm}, 2.7 \mu \mathrm{m})$ (Restek Raptor ${ }^{\circledR}$, Bellefonte, PA, USA). Injection volume was $10 \mu \mathrm{L}$, column temperature $30^{\circ} \mathrm{C}$, and flow rate of 0.4 $\mathrm{mL} / \mathrm{min}$ at a gradient program of $A$ (ultrapure water with $0.1 \%$ acetic acid) and $5 \% B$ (acetonitrile) for 1 $\mathrm{min}, 35 \% \mathrm{~B}$ for $2.5 \mathrm{~min}$, returning to $5 \% \mathrm{~B}$ at $2.51 \mathrm{~min}$, and 5.5 minutes for equilibration; total run time was $5.5 \mathrm{~min}$. EtS was analyzed in the negative ionization mode (ESI-).

Specific MS parameters such as fragmentor voltage and collision energies (CE) were optimized. The selected fragment ions and CE used for the instrumental analysis are shown in Table 1 including retention times, calibration ranges, and limits of quantitations (LOQs) for all target analytes. Limits of detections (LODs) and LOQs of target substances have been determined using US Environmental Protection Agency (USEPA) guidelines (USEPA 2016). Method recoveries were tested in the range of $85-114 \%$. LODs for illicit drugs were estimated between $0.5-2.5 \mathrm{ng} / \mathrm{L}$; for EtS $0.03 \mathrm{ng} / \mathrm{mL}$ and for cotinine $0.01 \mathrm{ng} / \mathrm{mL}$. The methods correlation coefficients were higher than 0.99 . Quality control (QC) samples at three levels $(50,150$ and 250 $\mathrm{ng} / \mathrm{L}$ for illicit drugs; $1,3,5 \mathrm{ng} / \mathrm{L}$ for cotinine; 1,5 and $25 \mathrm{ng} / \mathrm{mL}$ for EtS) were prepared which spiked with deuterated internal standards. 
Table 1

LC-ESI-MS/MS parameters established for the MRM acquisition mode of targeted compounds with retention times and limits of quantitation (LOQ)

\begin{tabular}{|c|c|c|c|c|c|c|c|c|c|}
\hline $\begin{array}{l}\text { Drug } \\
\text { Name }\end{array}$ & $\begin{array}{l}\text { Ret. } \\
\text { Time } \\
\text { (min) }\end{array}$ & $\begin{array}{l}\text { Calibration } \\
\text { range } \\
\text { (ng/L) }\end{array}$ & $\begin{array}{l}\text { LOQ } \\
\text { (ng/L) }\end{array}$ & $\begin{array}{l}\text { Recovery } \\
\text { (\%) }\end{array}$ & $\begin{array}{l}\text { Precursor } \\
(\mathrm{m} / \mathrm{z})\end{array}$ & $\begin{array}{l}\text { Product- } \\
1 \\
(\mathrm{~m} / \mathrm{z})\end{array}$ & $\begin{array}{l}\text { CE- } \\
1 \\
(V)\end{array}$ & $\begin{array}{l}\text { Product- } \\
2 \\
(\mathrm{~m} / \mathrm{z})\end{array}$ & $\begin{array}{l}\text { CE- } \\
2 \\
\text { (V) }\end{array}$ \\
\hline EtS & 3.5 & $\begin{array}{l}100- \\
100000\end{array}$ & 100 & 102.0 & 125.1 & 97.0 & 17 & 79.9 & 30 \\
\hline COT & 4.3 & $500-20000$ & 500 & 96.7 & 177.0 & 53.0 & -47 & 80.0 & -25 \\
\hline AMP & 8.7 & $5-200$ & 5.2 & 97.6 & 136.1 & 91.1 & -20 & 119.1 & -15 \\
\hline METH & 9.5 & $1-200$ & 1.4 & 93.4 & 150.1 & 91.1 & -20 & 119.1 & -15 \\
\hline MDMA & 9.7 & $2-200$ & 2.9 & 98.0 & 194.1 & 105.1 & -23 & 135.1 & -21 \\
\hline MOR & 4.9 & $1-200$ & 1.6 & 85.1 & 286.1 & 165.1 & -42 & 153.2 & -45 \\
\hline $\begin{array}{l}\text { THC- } \\
\mathrm{COOH}\end{array}$ & 9.0 & $5-200$ & 5.2 & 99.3 & 345.3 & 299.2 & -20 & 193.1 & -27 \\
\hline BE & 5.1 & $2-200$ & 2.5 & 103.5 & 290.1 & 168.1 & -19 & 105.1 & -30 \\
\hline EtS-d ${ }_{5}$ & 3.5 & & & & 130.0 & 98.0 & 19 & 80.0 & 28 \\
\hline $\mathrm{COT}-\mathrm{d}_{3}$ & 4.2 & & & & 180.0 & 80.0 & -26 & 101.0 & -25 \\
\hline BE-D3 & 5.0 & & & & 292.6 & 171.1 & -21 & 108.1 & -48 \\
\hline \multirow{2}{*}{$\begin{array}{l}\text { MOR- } \\
\text { D3 }\end{array}$} & 4.6 & & & & 289.2 & 165.0 & -43 & 201.1 & -28 \\
\hline & 8.9 & & & & 199.1 & 165.1 & -13 & 135.1 & -23 \\
\hline D5 & 9.2 & & & & 348.1 & 330.2 & -16 & 302.2 & -22 \\
\hline \multicolumn{10}{|l|}{$\begin{array}{l}\text { THC- } \\
\text { COOH- } \\
\text { D3 }\end{array}$} \\
\hline $\begin{array}{l}\text { min: min } \\
\text { methamp } \\
\Delta 9-T H C\end{array}$ & $\begin{array}{l}\mathrm{Vv} \\
\text { tami } \\
\text { boxy }\end{array}$ & $\begin{array}{l}\text { e, EtS: ethl } \\
\text { MDMA } 3,4-1\end{array}$ & $\begin{array}{l}\text { ulpha } \\
\text { hylen }\end{array}$ & $\begin{array}{l}\text { COT cotir } \\
\text { xymetha }\end{array}$ & $\begin{array}{l}\text { AMP am } \\
\text { hetamine }\end{array}$ & $\begin{array}{l}\text { tamine, } \\
\text { OR morph }\end{array}$ & $\begin{array}{l}\text { ETH } \\
\text { ie, Th }\end{array}$ & $\mathrm{COOH}:$ & nor- \\
\hline
\end{tabular}


The concentrations of measured biomarkers in wastewater were back-calculated considering additional information such as consumption in the target population, wastewater flow, the size of the population served by the WWTP, and applying a correction factor regarding human metabolism. Illicit drugs, nicotine and alcohol loads were back-calculated using the concentrations of the parent drug (AMPH, METH, MDMA, and morphine) or metabolite (BE for $\mathrm{COC}$, $\mathrm{THC}-\mathrm{COOH}$ for marijuana, cotinine for nicotine and EtS for ethanol) in wastewater, the daily average flow rate of WWTPs (L/day), and correction factors (COC: 3.59, AMPH: 3.3, METH: 2.3, MDMA: 1.5, HER: 3.04, THC_COOH: 152, nicotine: 0.45 and alcohol: 3320) (van Nuijs et al. 2011; Castiglioni et al. 2015; van Wel et al. 2016a; Mastroianni et al. 2017). The amount of therapeutic morphine was obtained and subtracted for heroin back-calculations (van Nuijs et al. 2011). Since morphine amount metabolized from codeine was about $10 \%$ of codeine dose (Bowery 2007), it was overlooked in this study. The amount of therapeutic morphine used in Adana Province during the sampling period was obtained from the Provincial Health Directorate for the region of Adana Province served by the WWTP. The back-calculation equations of Daglioglu et al. (2021) were used for illicit drugs, and of Guzel et al. (2020) for nicotine and alcohol. The age group of 15-64 used for the estimated consumptions per 1000 inhabitants. 15-64 age group population data obtained from the Turkey Statistics Agency (TUIK). The average number of cigarettes smoked by 1000 people per day was calculated using the average amount of nicotine absorbed by the body during smoking (1 to $1.5 \mathrm{mg}$ (Hukkanen et al. 2005)). Assuming the average of 1 to $1.5 \mathrm{mg}$ of nicotine in a piece of cigarette absorbed in the body, the number of cigarettes consumed was calculated (Koob and Le Moal 2006). Back calculation provides the estimation for the consumption amount of nicotine expressed as $\mathrm{mg} /$ day/1000 inhabitant (or piece of cigarette/day/1000 inhabitant) for COC, AMPH, METH, HER, MDMA, THC-COOH mg/day/1000 inhabitant and mL/day/1000 inhabitant alcohol all per person aged 15 to 64 .

\subsection{Statistical methods}

Statistical analysis was performed using IBM SPSS Statistics Version v25.0 (Armonk, NY: IBM Corp.). Comparing the loads of the groups was made with the t-test. One-way ANOVA or Tukey's post hoc analysis was used to compare the means of more than two groups, and two-way ANOVA was used to compare the means of multiple group variables when applicable $(p<0.05)$.

\section{Results And Discussion}

\subsection{Illicit drugs during normal week and Ramadan}

Figure 1 shows the per capita illicit drugs load normal week and during Ramadan. (note that the $y$-axis is different for each compound). All illicit drugs were detected in all samples. Table 2 shows the mean, standard deviation, minimum and maximum values of illicit drugs load measured during the normal week and during Ramadan. Average estimated consumption during normal week and during Ramadan were respectively calculated as $21 \mathrm{mg} /$ day $/ 1000$ inhabitants and $19 \mathrm{mg} /$ day/1000 inhabitants for COC; 8.9 $\mathrm{mg} /$ day/1000 inhabitants and $8.2 \mathrm{mg} /$ day/1000 inhabitants for AMPH, $8.5 \mathrm{mg} /$ day/1000 inhabitants and $7.6 \mathrm{mg} /$ day/1000 inhabitants for METH; $46 \mathrm{mg} /$ day/1000 inhabitants and $37 \mathrm{mg} /$ day/1000 inhabitants for HER; 84 mg/day/1000 inhabitants and 60 mg/day/1000 inhabitants for MDMA; 7187 mg/day/1000 
inhabitants and $5271 \mathrm{mg} /$ day/1000 inhabitants for THC-COOH. This is similar for all other illicit drugs, with a decrease in consumption observed during Ramadan.

Table 2

Per capita consumption estimates of illicit drugs

\begin{tabular}{|llll|}
\hline Illicit Drug & Sampling period & Per capita consumption estimates(mg/day/1000 inhabitant) \\
\cline { 3 - 4 } & & Mean \pm SD & Min-Max \\
\hline COC & Normal week & $21 \pm 4$ & $14 .-25$ \\
\hline AMP & Ramadan & $19 \pm 3$ & $15-23$ \\
\hline \multirow{2}{*}{ METH } & Normal week & $9 \pm 1$ & $7-11$ \\
\hline \multirow{2}{*}{ HER } & Ramadan & $8 \pm 1$ & $7-9$ \\
\hline \multirow{2}{*}{ Normal week } & $9 \pm 2$ & $6-11$ \\
\hline & Ramadan & $8 \pm 1$ & $6-9$ \\
\hline NDM & Rormal week & $46 \pm 7$ & $37-58$ \\
\hline \multirow{2}{*}{ THC-COOH } & Normal week & $84 \pm 15$ & $27-45$ \\
\hline & Ramadan & $60 \pm 12$ & $67-109$ \\
\hline & Ramad week & $7187 \pm 1973$ & $39-76$ \\
\hline
\end{tabular}

MDMA is a substance used mainly for recreational purposes (Vuori et al., 2014), and the decrease in the use of this substance means that the same people attend less to entertainment venues during this period. In the present study, the highest decrease during Ramadan was in MDMA with $29 \%$. The figure for MDMA estimated consumptions were between $67-109 \mathrm{mg} /$ day/1000 inhabitants in the normal week and between 39-76 mg/day/1000 inhabitants during Ramadan. A significant change was noted for MDMA during Ramadan period ( $p$ value: 0.009). In another study covering Adana between 2016-2017, the amount drug estimated consumption for MDMA was $130 \mathrm{mg} /$ day/1000 inhabitant (Daglioglu et al. 2019). MDMA values determined in both sampling periods in Adana Province are less than the estimated consumption determined in Greece (530 mg/day/1000 inhabitant) (Gatidou et al. 2016) and higher than the study conducted in China (1.5 mg/day/1000 inhabitant) (Khan et al. 2014).

$\mathrm{COC}$, the third least consumed substance in Adana, was observed to range between 14-25 mg/day/1000 inhabitants in the normal week and between $15-23 \mathrm{mg} /$ day/1000 inhabitant during Ramadan. The illicit drug observed the least change during the month of Ramadan is $\mathrm{COC}(8.6 \%)$. While there was no statistically significant difference for the consumption of COC during Ramadan ( $p$ value: 0.383 ). In a study conducted in 11 provinces in Turkey in 2020, the mean COC estimated consumption was reported as 14.07 
$\mathrm{mg} /$ day/1000 inhabitant (Daglioglu et al. 2021). Although COC estimated consumption values obtained in this study were higher than observed in China (2.8 mg/day/1000 inhabitant) (Khan et al. 2014) and Finland (3.5 mg/day/1000 inhabitant) (Kankaanpää et al. 2016), it was found to be lower than figures stated in many other studies cited in the literature (Gatidou et al. 2016; Mastroianni et al. 2017; Foppe et al. 2018; Mercan et al. 2019; Asicioglu et al. 2021).

In this study, METH was the least consumed illicit substance than other substances (meth mean value= $8.1 \mathrm{mg} /$ day/1000 inhabitant) followed by the second least consumed substance, AMPH. It was determined that the estimated consumption of $\mathrm{AMPH}$ and METH decreased quantitatively during Ramadan. But, this decrease was determined to be statistically insignificant (AMPH ( $p$ value: 0.165 ), METH ( $p$ value: 0.338$)$ ). When the relevant studies in the literature were investigated, the highest AMPH consumption was measured as $1537 \mathrm{mg} / \mathrm{day} / 1000$ inhabitants in a study conducted in 19 cities in Europe (Thomas et al. 2012). According to the EMCDDA's 2019 report, the lowest AMPH was detected below the Paris and Milan analysis limit (EMCDDA 2019a). The AMPH values obtained in the present study, which were $8.9 \mathrm{mg} /$ day/1000 inhabitant in the normal week and $8.2 \mathrm{mg} /$ day/1000 inhabitant in Ramadan, were well below the estimated consumption observed in many other studies $(41.8 \mathrm{mg} / \mathrm{day} / 1000$ inhabitant (Asicioglu et al. 2021), $61.4 \mathrm{mg} /$ day/1000 inhabitant (Mercan et al. 2019), $722.5 \mathrm{mg} /$ day/1000 inhabitant (Foppe et al. 2018), 90 mg/day/1000 inhabitant (Mastroianni et al. 2017)).

It was observed that estimated consumption of HER decreased statistically significantly during Ramadan compared to the average of normal week ( $37 \mathrm{mg} /$ day $/ 1000$ inhabitant; $46 \mathrm{mg} /$ day/1000 inhabitant respectively) ( $p$ value: 0.025 ). In a study conducted in Turkey, the mean HER estimated consumption was reported as $42 \mathrm{mg} /$ day/1000 inhabitant (Daglioglu et al. 2021). Likewise, in another study covering Adana, the amount of illicit drug estimated consumptionuse was reported as $31 \mathrm{mg} /$ day/1000 inhabitant for HER (Daglioglu, Guzel, and Kilercioglu 2019). When means of the results for the Adana city across the previous and the current study were compared, it was concluded that HER use state an increasing trend. In the current study, the average amount of HER use is well below the reported values for the USA (2495 $\mathrm{mg} /$ day/1000 inhabitant) (Foppe et al. 2018), but above the value obtained in Costa Rica (14 $\mathrm{mg} /$ day/1000 inhabitant) (Causanilles et al. 2017).

THC-COOH was identified as the most frequently used illicit drug, with an average of $7187 \pm 1973$ $\mathrm{mg} /$ day/1000 inhabitants in the normal week and $5271 \pm 1203 \mathrm{mg} /$ day/1000 inhabitants during Ramadan. There was no statistically significant difference for the consumption of marijuana ( $p$ value: 0.085) during Ramadan. Marijuana, originating primarily from western Balkans countries or Morocco, are the most frequently seized drugs in Turkey (EMCDDA 2019b). Regarding another study in Turkey for THC$\mathrm{COOH}$ consumption, the highest figures were observed predominantly in summer in Gaziantep (another city located near Adana), while it was the fall in Adana during which marijuana consumption was relatively high (Daglioglu et al. 2021).

There are studies utilizing WBE to evaluate and determine trends in illicit drugs, alcohol, and nicotine load during different short periods such as festivals and pandemics. Benaglia et al. (2020), in their study comparing the Australian festival with the Swiss Festival, reported that the amount of illicit drugs observed 
by wastewater analysis was consistent with the drug seizure statistics (Benaglia et al. 2020). Another study conducted on wastewater collected in 6 festivals in Europe reported that the most frequently detected drugs were cocaine, ecstasy, cannabis, and ketamine (Bijlsma et al. 2020). In the COVID-19 pandemic, a study conducted in the Austrian state of Tyrol stated that the consumption of recreational drugs (COC and MDMA) decreased during the quarantine process (Reinstadler et al. 2021). Finally, in another study conducted during the period of lockdown in the COVID-19 pandemic in European cities, it was reported that ecstasy levels decreased by $50 \%$ compared to previous years (Been et al. 2021).

\subsection{Nicotine and alcohol during normal week and Ramadan}

Table 3 shows the mean, standard deviation, minimum and maximum values of alcohol and nicotine load during the normal week and Ramadan. The average estimated nicotine consumption in a normal week was $2814 \mathrm{mg} /$ day/1000 inhabitant and during Ramadan it was 2119 mg/day/1000 inhabitant. Regarding alcohol, the consumption in a normal week was $4727 \mathrm{~mL} /$ day/1000 inhabitants and $3502 \mathrm{~mL} /$ day/1000 inhabitants during Ramadan.

Assuming that a single cigarette on avarage contains $1 \mathrm{mg}$ of nicotine, it was found that 2.8 cigarettes per person per day were smoked in a typical week, while the number of cigarettes consumed in Ramadan decreased to 2.1 per person per day. Turkey Tobacco and Alcohol Market Regulatory Authority (TAPDK) 2019 sales data indicate that daily cigarette consumption per person of 2.1 cigarettes. While the average of tobacco use obtained in this study was similar to TAPDK data, it was lower than the value of 4.7 cigarettes reported by the Global Adult Tobacco Survey in 2015 (Asma et al. 2015).

In 2015 the per capita annual alcohol consumption in Turkey was $1.4 \mathrm{~L}$ of pure alcohol, and according to 2010 World Health Organization (WHO) data, alcoholic beverage consumption in Turkey was reported to account for approximately one-third of the world average (Buzrul 2016). In a study conducted between 2016 and 2017 using WBE in Adana, the annual alcohol estimatited consumption per person (+15 age) was 1.5 L (Daglioglu et al. 2020), while in 2019, it was 1.8 L (Guzel et al. 2020).

Table 3

Per capita consumption estimates of nicotine and alcohol

\begin{tabular}{|llll|}
\hline & Sampling period & \multicolumn{2}{l|}{ Per capita consumption estimates } \\
\cline { 3 - 4 } & & Mean \pm SD & Min-Max \\
\hline NIC & Normal week & $2811 \pm 257$ & $2449-3164$ \\
(mg/day/1000 inhabitant) & Ramadan & $2119 \pm 310$ & $1435-2372$ \\
\hline ALC & Normal week & $4727 \pm 633$ & $4267-6100$ \\
(mL/day/1000 inhabitant) & Ramadan & $3502 \pm 772$ & $2113-4522$ \\
\hline
\end{tabular}

The nicotine metabolite cotinine and the alcohol metabolite EtS were measured in all samples. Decreases in nicotine and alcohol loads per person during Ramadan and the normal week (note that the $y$-axis is different for each compound) were observed (Fig. 2). There was a $26 \%$ reduction in alcohol consumption 
and $25 \%$ regarding nicotine consumption. Therefore, a statistically significant change was detected in the estimated consumption of nicotine and alcohol during Ramadan. Similarly, in the study of Çelen (2014), it was found that the month of Ramadan was associated with lower alcohol use. Similarly, when the literature was reviewed, it was found that there was an inverse relationship between church attendance and excessive drinking behavior (Michalak et al. 2007). When comparing the days, a significant decrease was found in alcohol and nicotine consumption on Friday during Ramadan (Fig. 2). Friday is a holy day of worship for Muslims. Especially in Ramadan, as they give more importance to worship, nicotine and alcohol use decreases even more on Fridays in this month.

In the current study, the average estimated consumption of nicotine $(2119 \mathrm{mg} / \mathrm{day} / 1000$ inhabitant $)$ and alcohol (3502 ml/day/1000 inhabitant) detected during Ramadan was found to be lower than the amounts observed in previous studies conducted in Adana (Daglioglu et al. 2020). In a study on alcohol consumption conducted in Turkey, the average estimated consumption varied from 1687.8 to 5657.8 $\mathrm{mL} /$ day/1000 inhabitants (Guzel et al. 2020) with an average of $4865.8 \mathrm{~mL} /$ day/1000 inhabitants. In the same study, nicotine consumption in Turkey varied from 987 to $4281 \mathrm{mg} /$ day/1000 inhabitant, and the average was $2911.5 \mathrm{mg} /$ day/1000 inhabitants.

In the study of Ghouri et al., (2006), it was reported that smoking would probably decrease during Ramadan, as smokers would not be able to smoke during the fasting period, that is, during the daylight. Studies reported that the onset of Ramadan was used as an incentive to encourage stopping smoking since obligatory non-smoking during Ramadan could cause many regular smokers to quit (Ghouri et al. 2006; Aveyard et al. 2011; Hershkop and Bisharat 2020). In this study, it was determined that nicotine use decreased in Ramadan, which confirms the results of the previous studies.

There is no study reporting the number of fasting people for Adana province. There are also studies showing that, during Ramadan, Muslim patients arbitrarily change their prescription drug regimen without any medical consultation (Aslam and Assad 1986; Aadil et al. 2004). This study compared the use of 6 types of illicit drugs (cocaine, amphetamine, methamphetamine, ecstasy, heroin and marijuana), alcohol and nicotine using WBE between the month of Ramadan and the normal period in Turkey and showed that the use of all these substances decreased during Ramadan.

\subsection{Uncertainties and limitations of the study}

Studies using the WBE approach have some uncertainties and limitations, such as sampling, chemical analysis, stability of biomarkers in wastewater, limitations in backcalculation (eg, calculate population size). The standard uncertainties and limitations for alcohol and tobacco biomarkers were instrumental measurement (i.e., errors in flowmeter measurement, calibration errors), real-time population estimation, the large variance of nicotine among each cigarette (0.4-1.2 $\mathrm{mg})$ in different brands, and differences in the excretion factor due to influences of gender, diet, enzymes, age, and drug usage. Each of these limits is likely to affect per capita substance consumption calculations. Despite its limitations, WBE makes an important contribution to profiling drug consumption in real time, where official methods are lacking and monitoring changing trends. 


\section{Conclusions}

During Ramadan, a significant decrease relative to other months in the consumption of MDMA, HER, nicotine, and alcohol was detected by WBE, but not of $\mathrm{COC}$, AMPH, METH, and THC-COOH. Therefore, the study presented that wastewater epidemiology is a appropriate method for evaluating consumption of illicit drugs, alcohol, and nicotine during different short periods such as festivals and pandemics via choosing the correct sampling periods. This study is the first to show changes in use of illicit drugs, alcohol and nicotine under the influence of religious beliefs. There is no enough data about illicit drugs, alcohol and nicotine abusers/users in Ramadan. Also, this study could contribute to anti-drug strategies.

\section{Declarations}

\section{Acknowledgements}

The author would like to thank Asli Atasoy and Ismail Ethem Goren for their valuable technical support in field and laboratory studies. This study was presented as "Best poster" at the conference "Testing Waters 5" (Brisbane, 28 September - 1 October 2021).

\section{Ethical Approval}

Not applicable.

\section{Consent to Participate}

Not applicable.

\section{Consent to Publish}

Not applicable.

\section{Author Contributions}

All of the research, methodology, validation, data curation, original drafting, writing, visualization and editing were done by the author Evsen Yavuz Guzel.

\section{Funding}

The author did not receive support from any organization for the submitted work.

\section{Conflict of interest}

The author declares no conflict of interest.

\section{Availability of data and materials}

All data generated in this study is found in this manuscript. 


\section{References}

Aadil N, Houti IE, Moussamih S (2004) Drug intake during Ramadan. Br Med J 329:778-782. https://doi.org/10.1136/bmj.329.7469.778

Asicioglu F, Kuloglu Genc M, Tekin Bulbul T, et al (2021) Investigation of temporal illicit drugs, alcohol and tobacco trends in Istanbul city: Wastewater analysis of 14 treatment plants. Water Res 190:116729. https://doi.org/10.1016/j.watres.2020.116729

Aslam M, Assad A (1986) Drug regimens and fasting during Ramadan: A survey inKuwait. Public Health 100:49-53. https://doi.org/10.1016/S0033-3506(86)80086-5

Asma S, Mackay J, Song SY, et al (2015) Global adult tobacco survey.

http://gatsatlas.org/pdf/mobile/index.html\#p=90. Accessed 5 Apr 2021

Aveyard P, Begh R, Sheikh A, Amos A (2011) Promoting smoking cessation through smoking reduction during Ramadan. Addiction 106:1379-1380

Been F, Emke E, Matias J, et al (2021) Changes in drug use in European cities during early COVID-19 lockdowns - A snapshot from wastewater analysis. Environ Int 153:106540.

https://doi.org/10.1016/j.envint.2021.106540

Benaglia L, Udrisard R, Bannwarth A, et al (2020) Testing wastewater from a music festival in Switzerland to assess illicit drug use. Forensic Sci Int 309:1-8. https://doi.org/10.1016/j.forsciint.2020.110148

Bijlsma L, Celma A, Castiglioni S, et al (2020) Monitoring psychoactive substance use at six European festivals through wastewater and pooled urine analysis. Sci Total Environ 725:.

https://doi.org/10.1016/j.scitotenv.2020.138376

Bowery NG (2007) Codeine. xPharm Compr Pharmacol Ref 1-4. https://doi.org/10.1016/B978008055232-3.61504-1

Buzrul S (2016) Alcohol Consumption in Turkey. J Food Heal Sci 2:112-122. https://doi.org/10.3153/jfhs16012

Castiglioni S, Bijlsma L, Covaci A, et al (2013) Evaluation of uncertainties associated with the determination of community drug use through the measurement of sewage drug biomarkers. Environ Sci Technol 47:1452-1460. https://doi.org/10.1021/es302722f

Castiglioni S, Senta I, Borsotti A, et al (2015) A novel approach for monitoring tobacco use in local communities by wastewater analysis. Tob Control 24:38-42. https://doi.org/10.1136/tobaccocontrol2014-051553

Castiglioni S, Zuccato E, Crisci E, et al (2006) Identification and Measurement of Illicit Drugs and Their Metabolites in Urban Wastewater by Liquid Chromatography-Tandem Mass Spectrometry. Anal Chem 
Causanilles A, Kinyua J, Ruttkies C, et al (2017) Qualitative screening for new psychoactive substances in wastewater collected during a city festival using liquid chromatography coupled to high-resolution mass spectrometry. Chemosphere 184:1186-1193. https://doi.org/10.1016/j.chemosphere.2017.06.101

Çelen A (2015) Influence of Holy Month Ramadan on Alcohol Consumption in Turkey. J Relig Health 54:2122-2133. https://doi.org/10.1007/s10943-014-9875-6

Daglioglu N, Atasoy A, Asadi A, et al (2020) Estimating alcohol consumption by using wastewater-based epidemiology in Adana Province, Turkey. Environ Sci Pollut Res 27:31884-31891.

https://doi.org/10.1007/s11356-020-09056-w

Daglioglu N, Guzel EY, Atasoy A, Gören IE (2021) Comparison of community illicit drug use in 11 cities of Turkey through wastewater-based epidemiology. Environ Sci Pollut Res 28:15076-15089.

https://doi.org/10.1007/s11356-020-11404-9

Daglioglu N, Guzel EY, Kilercioglu S (2019) Assessment of illicit drugs in wastewater and estimation of drugs of abuse in Adana Province, Turkey. Forensic Sci Int 294:132-139.

https://doi.org/10.1016/j.forsciint.2018.11.012

EMCDDA (2016) Wastewater analysis and drugs: a European multi-city study. 1-5.

https://doi.org/http://www.emcdda.europa.eu/topics/pods/waste-water-analysis

EMCDDA (2021) Perspectives on Drugs-Wastewater analysis and drugs: a European multi-city study

EMCDDA (2019a) Wastewater analysis and drugs: a European multi-city study

EMCDDA (2019b) Turkey Country Drug Report 2019

European Comission (EC) (2019) Demographic situation: Turkey. https://eacea.ec.europa.eu/nationalpolicies/eurydice\%0Ahttps://eacea.ec.europa.eu/national-policies/eurydice/content/populationdemographic-situation-languages-and-religions-103_en

Foppe KS, Hammond-Weinberger DR, Subedi B (2018) Estimation of the consumption of illicit drugs during special events in two communities in Western Kentucky, USA using sewage epidemiology. Sci Total Environ 633:249-256. https://doi.org/10.1016/j.scitotenv.2018.03.175

Gao T, Du P, Xu Z, Li X (2017) Occurrence of new psychoactive substances in wastewater of major Chinese cities. Sci Total Environ 575:963-969. https://doi.org/10.1016/j.scitotenv.2016.09.152

Gatidou G, Kinyua J, van Nuijs ALN, et al (2016) Drugs of abuse and alcohol consumption among different groups of population on the Greek Island of Lesvos through sewage-based epidemiology. Sci Total Environ 563-564:633-640. https://doi.org/10.1016/j.scitotenv.2016.04.130 
Ghouri N, Atcha M, Sheikh A (2006) Public health Influence of Islam on smoking among Muslims. BMJ 332:

Guzel EY, Atasoy A, Gören IE, Daglioglu N (2020) Estimation of alcohol and nicotine consumption in 11 cities of Turkey using wastewater-based epidemiology. Drug Test Anal. https://doi.org/10.1002/dta.2979

Hershkop E, Bisharat B (2020) Ramadan and smoking cessation. Isr Med Assoc J 22:264

Hukkanen J, Jacob P, Benowitz NL (2005) Metabolism and disposition kinetics of nicotine. Pharmacol Rev 57:79-115. https://doi.org/10.1124/pr.57.1.3

Kankaanpää A, Ariniemi K, Heinonen M, et al (2016) Current trends in Finnish drug abuse: Wastewater based epidemiology combined with other national indicators. Sci Total Environ 568:864-874. https://doi.org/10.1016/j.scitotenv.2016.06.060

Khan U, van Nuijs ALN, Li J, et al (2014) Application of a sewage-based approach to assess the use of ten illicit drugs in four Chinese megacities. Sci Total Environ 487:710-721.

https://doi.org/10.1016/j.scitotenv.2014.01.043

Koob GF, Le Moal M (2006) Nicotine. In: Neurobiology of Addiction. Elsevier, pp 243-287

Kuloglu M, Mercan S, Yayla M, et al (2021) Monitoring geographical differences in illicit drugs, alcohol , and tobacco consumption via wastewater-based epidemiology: Six major cities in Turkey. Sci Total Environ 797:149156. https://doi.org/10.1016/j.scitotenv.2021.149156

Lorenzo M, Picó Y (2019) Wastewater-based epidemiology: current status and future prospects. Curr Opin Environ Sci Heal 9:77-84. https://doi.org/10.1016/j.coesh.2019.05.007

Mackul'ak T, Grabic R, Gál M, et al (2015) Evaluation of different smoking habits during music festivals through wastewater analysis. Environ Toxicol Pharmacol 40:1015-1020.

https://doi.org/10.1016/j.etap.2015.10.007

Mackul'ak T, Brandeburová P, Grenčíková A, et al (2019) Music festivals and drugs: Wastewater analysis. Sci Total Environ 659:326-334. https://doi.org/10.1016/j.scitotenv.2018.12.275

Mastroianni N, López-García E, Postigo C, et al (2017) Five-year monitoring of 19 illicit and legal substances of abuse at the inlet of a wastewater treatment plant in Barcelona (NE Spain) and estimation of drug consumption patterns and trends. Sci Total Environ 609:916-926.

https://doi.org/10.1016/j.scitotenv.2017.07.126

Mercan S, Kuloglu M, Tekin T, et al (2019) Wastewater-based monitoring of illicit drug consumption in Istanbul: Preliminary results from two districts. Sci Total Environ 656:231-238.

https://doi.org/10.1016/j.scitotenv.2018.11.345 
Metcalfe C, Tindale K, Li H, et al (2010) Illicit drugs in Canadian municipal wastewater and estimates of community drug use. Environ Pollut 158:3179-3185. https://doi.org/10.1016/j.envpol.2010.07.002

Michalak L, Trocki K, Bond J (2007) Religion and alcohol in the U.S. National Alcohol Survey: How important is religion for abstention and drinking? Drug Alcohol Depend 87:268-280.

https://doi.org/10.1016/j.drugalcdep.2006.07.013

Ort C, van Nuijs ALN, Berset J-D, et al (2014) Spatial differences and temporal changes in illicit drug use in Europe quantified by wastewater analysis. Addiction 109:1338-1352. https://doi.org/10.1111/add.12570

Reinstadler V, Ausweger V, Grabher AL, et al (2021) Monitoring drug consumption in Innsbruck during coronavirus disease 2019 (COVID-19) lockdown by wastewater analysis. Sci Total Environ 757:144006. https://doi.org/10.1016/j.scitotenv.2020.144006

Thomas K V., Bijlsma L, Castiglioni S, et al (2012) Comparing illicit drug use in 19 European cities through sewage analysis. Sci Total Environ 432:432-439. https://doi.org/10.1016/j.scitotenv.2012.06.069

USEPA (2016) Definition and Procedure for the Determination of the Method Detection Limit, Revision 2

van Nuijs ALN, Castiglioni S, Tarcomnicu I, et al (2011) Illicit drug consumption estimations derived from wastewater analysis: A critical review. Sci Total Environ 409:3564-3577.

https://doi.org/10.1016/j.scitotenv.2010.05.030

van Wel JHP, Gracia-Lor E, van Nuijs ALN, et al (2016a) Investigation of agreement between wastewaterbased epidemiology and survey data on alcohol and nicotine use in a community. Drug Alcohol Depend 162:170-175. https://doi.org/10.1016/j.drugalcdep.2016.03.002

van Wel JHP, Kinyua J, van Nuijs ALN, et al (2016b) A comparison between wastewater-based drug data and an illicit drug use survey in a selected community. Int J Drug Policy 34:20-26.

https://doi.org/10.1016/j.drugpo.2016.04.003

Verovšek T, Krizman-Matasic I, Heath D, Heath E (2020) Site- and event-specific wastewater-based epidemiology: Current status and future perspectives. Trends Environ Anal Chem 28:. https://doi.org/10.1016/j.teac.2020.e00105

Zarei S, Salimi Y, Repo E, et al (2020) A global systematic review and meta-analysis on illicit drug consumption rate through wastewater-based epidemiology. Environ Sci Pollut Res 27:36037-36051. https://doi.org/10.1007/s11356-020-09818-6

Zuccato E, Castiglioni S, Fanelli R (2005) Identification of the pharmaceuticals for human use contaminating the Italian aquatic environment. J Hazard Mater 122:205-209.

https://doi.org/10.1016/j.jhazmat.2005.03.001

\section{Figures}




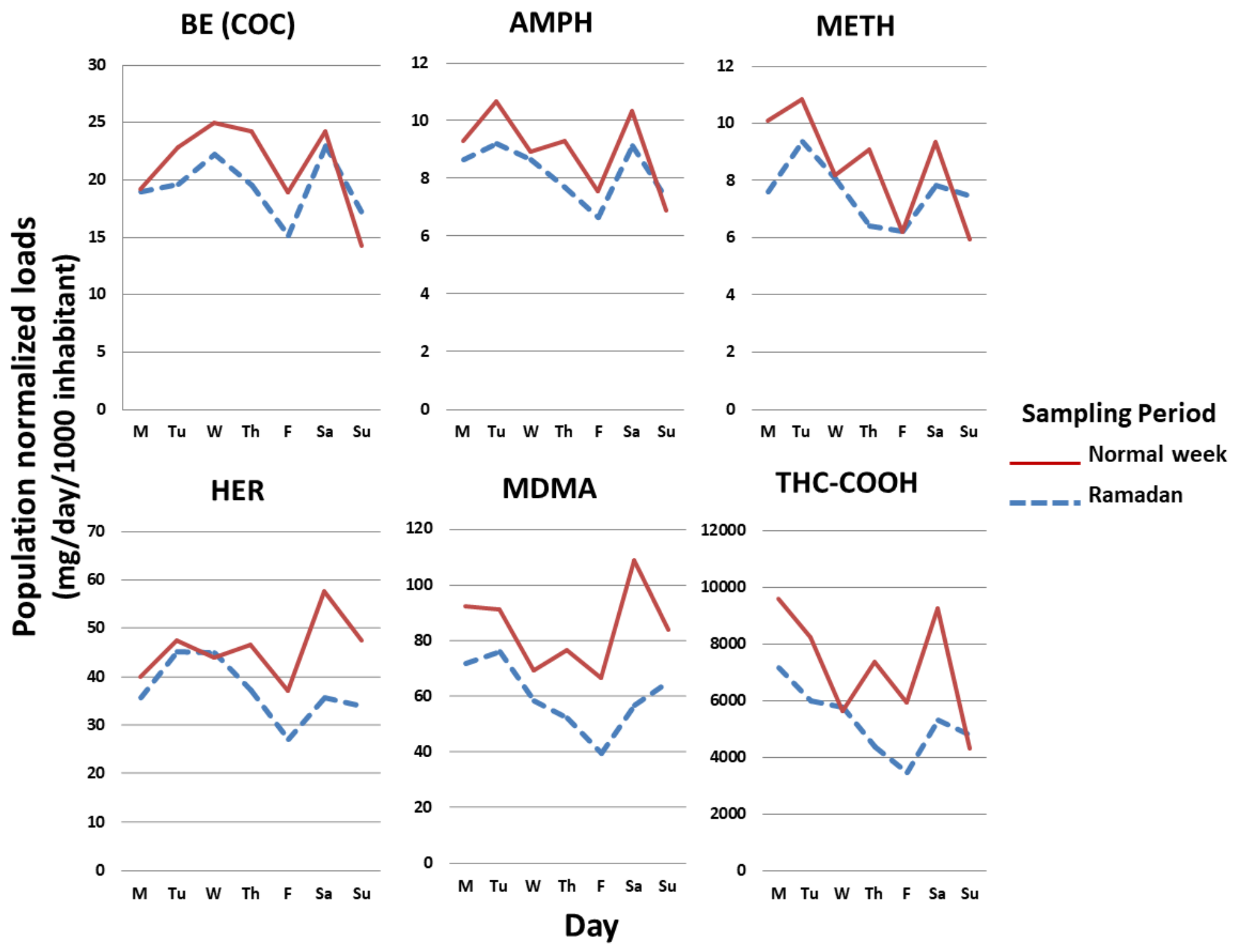

Figure 1

Weekly pattern of population normalized loads for illicit drugs during Ramadan and a normal week. 
NIC

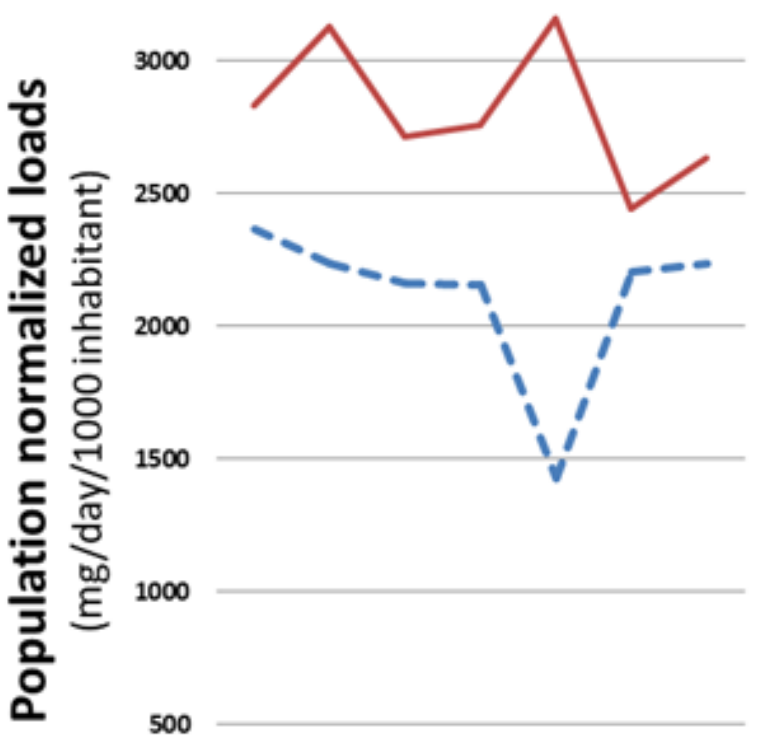

0

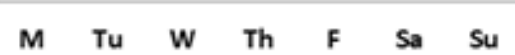

ALC

7000

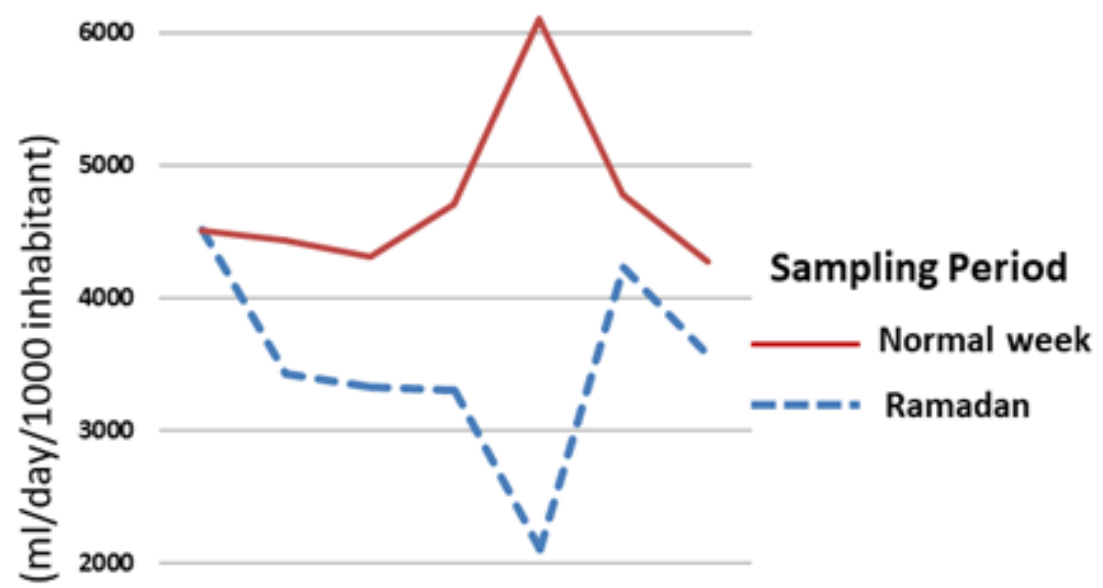

1000

0

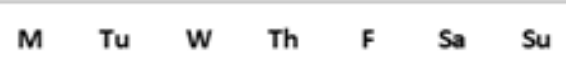

\section{Day}

Figure 2

Weekly pattern of population normalized loads for nicotine (NIC) and alcohol (ALC) during Ramadan and a normal week.

\section{Supplementary Files}

This is a list of supplementary files associated with this preprint. Click to download.

- GRAPHICALABSTRACT.png 